\title{
EVALUATION OF MECHANICAL BEHAVIOUR OF GLASS FIBRE-EPOXY WITH GRAPHENE NANO POWDER LAMINATES
}

\author{
Dr. JALLEDA ANJANEYULU ${ }^{1}$, V. HARSHA VARDHAN ${ }^{2}$ \& P.CHANDRA KUMAR ${ }^{3}$ \\ ${ }^{I}$ Senior Assistant Professor, Department of Mechanical Engineering, Vasavi College of Engineering, Hyderabad, \\ Telangana, India \\ ${ }^{2}$ Student, Department of Mechanical Engineering, Vasavi College of Engineering, Hyderabad, Telangana, India \\ ${ }^{3}$ Scholar, Gitam University, Hyderabad, Telangana, India
}

\begin{abstract}
This paper presents the fabrication and evaluation of Glass fiber reinforced-epoxy with addition of graphene nano powder laminates as per the ASTM (American Society for testing and Materials) standards. The composites are made by using epoxy as a structural matrix material which is reinforced by glass fibre to enhance the strength. The strength of composite material depends on the amount of fibre and matrix content which are indicated by fibre matrix volume fractions. The fibre orientation plays a vital role in the strength of composites.

Symmetric and anti-symmetric cross ply laminates of uni directional E-Glass Fiber reinforced epoxy are fabricated by using hand layup process with the help of moulds of required shape. The mechanical properties of tensile, impact and flexural strengths of fabricated composites are found by conducting experiments such as tensile, impact and flexural tests respectively. Burn test is performed on laminates to find the volume fractions of both fiber and matrix to calculate orthotropic properties of symmetric and anti-symmetric cross ply laminates. Deflections and stresses of symmetric and anti-symmetric cross ply laminates are found using numerical analysis ANSYS software. Experimental and numerical analysis results are compared. After ascertaining the superiority in strength of symmetric cross ply laminate, Graphene nano powder as filler material is added to them and analysed. The improvements of strength for the symmetric laminate with graphene nano powder are presented.
\end{abstract}

KEYWORDS: ANSYS-ACP, Graphene Nano Powder, MATLAB, Symmetric \&Anti-Symmetric Cross-Ply Laminates

Received: Jun 08, 2020; Accepted: Jun 28, 2020; Published: Sep 17, 2020; Paper Id.: IJMPERDJUN20201299

\section{INTRODUCTION}

The Composites are utilized all over the world to avail construct and rehabilitate a wide variety of infrastructures, that are being extensively utilized in the aerospace, automobile industry, sports, transportation, architecture and infrastructure industry.

"A composite material is composed of reinforcement (particles, fibres, flakes or fillers) embedded in a cured resin also known as a matrix (polymer, metals, ceramics). The fibre-reinforced composite materials (FRP) are generally preferred over the conventional materials due to its materials properties such as high specific strength, specific stiffness, toughness, lightweight and superior in-plane properties. Fibre-reinforced composites were successfully utilized for many decades for all engineering applications. Glass fibre reinforced polymeric (GFRP) composites was most commonly utilized in the manufacture of composite materials in industries. The mechanical properties of fibre-reinforced composites fundamentally depend on fibre strength and modulus, chemical stability, matrix strength, and the interface bond between fibre/ matrix to achieve stress transfer. Appropriate fibre composition 
and orientation make GFRP composites have the required performance and useful properties, which are equivalent to steel, have higher stiffness than aluminum, and have a specific gravity of $1 / 4$ of steel. The various Glass Fibre reinforcements like long longitudinal are randomly arranged, flattened into a sheet (called a chopped fibre mat), woven mat into a fabric and chopped mat in the composites have been produced to enhance the mechanical and tribological properties of the composites.

Composite materials have an in depth vary of commercial applications and laminated Glass fibre reinforced composite materials are employed in the automotive trade industry, marine industry and piping industries due to good ecological resistance, better damage tolerance for impact loading, high specific strength and stiffness, vibration damping, high fatigue strength etc.TP Sathish Kumar (1) outlines the different types of glass fibres and their correspondingphysical properties [1]. Glass fibres are having excellent properties like high strengthflexibility,

stiffness and resistance to chemical harm. Preparation of GFRP matrixcomposites using various techniques such as Hand Layup method, compression mouldinghot press technique, etc. were briefly discussed.Guru Raja M. N (2)adoptedVacuumbagging technique for the fabrication of hybrid specimens [3]. Three orientations $0^{\circ} / 90^{\circ}, 45^{\circ} / 45^{\circ}$ and $30^{\circ} / 60^{\circ}$ were considered for studies. Mechanicalproperties such as Tension strength, Tension modulus, \& peak load of the hybridcomposites were determined as per ASTM standards[4,5]. It was observed that angle plyorientation at $0^{\circ} / 90^{\circ}$ showed a significant increase in Tension properties as compared toother orientation[6].Nagabhushan (7)describes the damping and vibrationproperties of E-glass reinforced composite laminates are investigated by incorporatingdifferent contents $(0.1 \%$, $0.5 \%$ and $1 \%$ wt.) of Graphene oxide filler and compared withneat E-glass/epoxy composite laminates. At $0.5 \%$ graphene oxide indicates better damping behaviour $[8,9,10]$.

\section{LAMINATE TESTING}

\section{Laminate Preparation for Symmetric and Anti-Symmetric Cross-Ply Laminate}

Compressive matched die mould hand layup technique was used for preparing this laminate. The orientation considered for this symmetric cross-ply laminate is $\left(0^{\circ} / 90^{\circ} / 90^{\circ} / 0^{\circ}\right)$ and anti-symmetric cross-ply laminate is $\left(0^{\circ} / 90^{\circ} / 0^{\circ} / 90^{\circ}\right)$. The fibre matrix volume fraction was maintained as 50-50 i.e. volume fractions of fibre and matrix were maintained at a ratio of 1:1. Whereas, the ratio of resin and hardener was maintained as 1:10. Total weight of four plies of the symmetric cross-ply laminate was 750 grams. Therefore 750 grams of resin was mixed with 75 grams of hardener using a stirrer. This resin hardener mixture was applied on each glass fibre ply as per hand layup procedure.

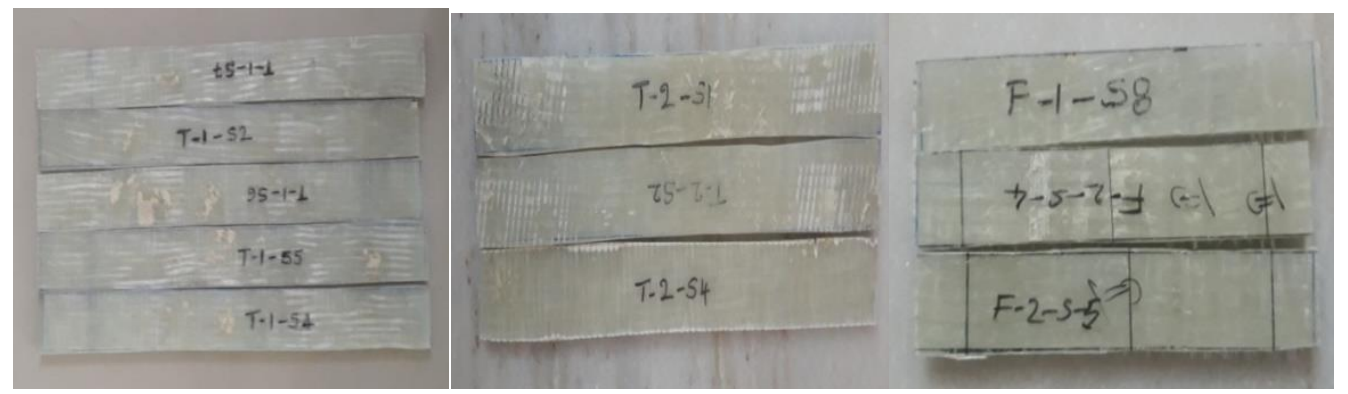

a. Symmetric Laminate Tension b.Anti-Symmetric Laminate Tension

c. Bending Symmetric and anti-symmetric

Figure 1: Specimens For Testing. 


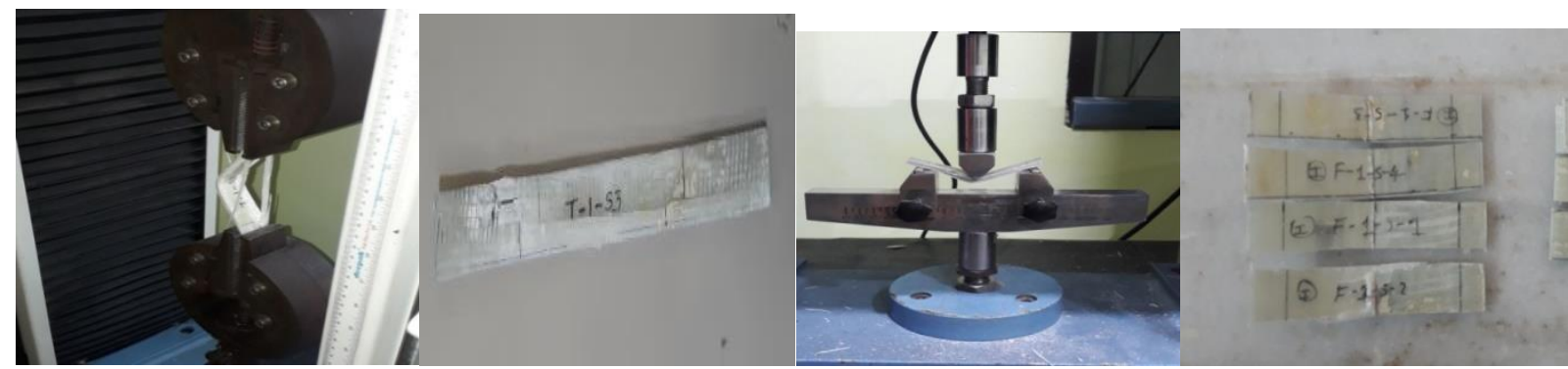

a.Tension Testingb.. b.Fractured Tension Specimen

a.Bending Testing b.. Fractured Bending Specimen

Figure 2: Tension Test using UTM. Figure 3: Bending Test on 3 Point Bending Machine.

From tensile test it has been observed that the symmetric cross ply laminate has maximum average tensile strength of 202.09 MPa than Anti-symmetric cross ply laminate average tensile strength of 196.8 MPa.

From 3-point bending test, it has been observed that the symmetric cross ply laminate has maximum average flexural strength of 394.6 MPa than Anti-symmetric cross ply laminate average flexural strength of $371.87 \mathrm{MPa}$.As symmetric cross ply laminate has better mechanical properties than anti-symmetric cross ply laminate, symmetric cross ply laminate with addition of Graphene nano powder material is added for further analysis of cross ply laminates.

\section{THEORETICAL ANALYSIS USING MATLAB}

The micro mechanics of lamina is analyzed for the considered glass fiber and Epoxy strength properties. The volume fraction of the fibre is considered as $50 \%$. After finding the Lamina properties the macro mechanics of composite is anlyzed to find Transformed stifness \& compliance matrices and the A, B, D matrices and further stresses and strains of the considered laminates.For transformed reduced stiffness of the laminates considered [0/90/90/0], [0/90/0/90], [-45/45/45/-45] and [$45 / 45 /-45 / 45]$, the program used in MATLAB is given as :

\% Transformed Reduced Stiffness:

function [y1 y2 y3 y4]= Qbar(Q,theta)

\%Qbar This function returns the transformed reduced.\% stiffness matrix "Qbar" given the reduced.

$\%$ stiffness matrix Q and the orientation.\% angle "theta".\% There are two arguments representing Q and "theta" $\%$ The size of the matrix is $3 \times 3 . \%$ The angle "theta" must be given in degrees.

theta $1=0$; theta $2=90 ;$ theta $3=-45 ;$ theta $4=+45$;

$\mathrm{m} 1=\cos ($ theta $1 * \mathrm{pi} / 180) ; \mathrm{n} 1=\sin ($ theta $1 * \mathrm{pi} / 180)$

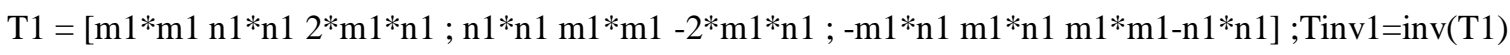

$\mathrm{m} 2=\cos ($ theta $2 *$ pi $/ 180) ; \mathrm{n} 2=\sin ($ theta $2 *$ pi $/ 180) ;$

$\mathrm{T} 2=\left[\mathrm{m} 2 * \mathrm{~m} 2 \mathrm{n} 2 *_{\mathrm{n}} 22^{*} \mathrm{~m} 2 *_{\mathrm{n}} 2 ; \mathrm{n} 2 *_{\mathrm{n}} 2 \mathrm{~m} 2 *_{\mathrm{m}} 2-2 * \mathrm{~m} 2 *_{\mathrm{n}} 2 ;-\mathrm{m} 2 *_{\mathrm{n}} 2 \mathrm{~m} 2 *_{\mathrm{n}} 2 \mathrm{~m} 2 * \mathrm{~m} 2-\mathrm{n} 2 * \mathrm{n} 2\right] ; \operatorname{Tinv} 2=\operatorname{inv}(\mathrm{T} 2)$

$\mathrm{m} 3=\cos ($ theta $3 * \mathrm{pi} / 180) ; \mathrm{n} 3=\sin ($ theta $3 *$ pi $/ 180) ;$

$\mathrm{T} 3=\left[\mathrm{m} 3 *^{*} \mathrm{~m} 3 \mathrm{n} 3 *_{\mathrm{n}} 32{ }^{*} \mathrm{~m} 3 *_{\mathrm{n}} 3 ; \mathrm{n} 3 *^{\mathrm{n}} 3 \mathrm{~m} 3 *^{*} \mathrm{~m} 3-2 *^{*} \mathrm{~m} 3 *_{\mathrm{n}} 3 ;-\mathrm{m} 3 *_{\mathrm{n}} 3 \mathrm{~m} 3 *_{\mathrm{n}} 3 \mathrm{~m} 3 *^{*} \mathrm{~m} 3-\mathrm{n} 3 *_{\mathrm{n}} 3\right] ; \operatorname{Tinv} 3=\operatorname{inv}(\mathrm{T} 3)$

$\mathrm{m} 4=\cos ($ theta $4 * \mathrm{pi} / 180) ; \mathrm{n} 4=\sin ($ theta $4 * \mathrm{pi} / 180) ;$ 
$\mathrm{T} 4=\left[\mathrm{m} 4 * \mathrm{~m} 4 \mathrm{n} 4 *_{\mathrm{n}} 42 * \mathrm{~m} 4 *_{\mathrm{n}} 4 ; \mathrm{n} 4 *_{\mathrm{n}} 4 \mathrm{~m} 4 * \mathrm{~m} 4-2 * \mathrm{~m} 4 * \mathrm{n} 4 ;-\mathrm{m} 4 * \mathrm{n} 4 \mathrm{~m} 4 *_{\mathrm{n}} 4 \mathrm{~m} 4 * \mathrm{~m} 4-\mathrm{n} 4 * \mathrm{n} 4\right] ; \operatorname{Tinv} 4=\mathrm{inv}(\mathrm{T} 4)$

$\% \operatorname{Tinv} 1=[m * m n * n-2 * m * n ; n * n+m * m 2 * m * n ; m * n-m * n m * m-n * n] ;$

$Q=[37.51881 .07520 ; 1.07524 .30090 ; 0003.2177]$

$[\mathrm{y} 1]=[\operatorname{Tinv} 1 * \mathrm{Q} * \mathrm{~T} 1] ;[\mathrm{y} 2]=[\mathrm{Tinv} 2 * \mathrm{Q} * \mathrm{~T} 2] ;[\mathrm{y} 3]=[\operatorname{Tinv} 3 * \mathrm{Q} * \mathrm{~T} 3] ;[\mathrm{y} 4]=[\mathrm{Tin} v 4 * \mathrm{Q} * \mathrm{~T} 4]$.

The material properties obtained from the analysis are tabulated in Table.1, which will be used in the ANSYS.

Table 1: Material Properties of Laminates

\begin{tabular}{|l|c|c|c|c|c|c|c|c|c|}
\hline \multicolumn{1}{|c|}{ Type of Laminate } & $\begin{array}{c}\mathbf{E}_{\mathbf{x}} \\
(\mathbf{M p a})\end{array}$ & $\begin{array}{c}\mathbf{E}_{\mathbf{y}} \\
(\mathbf{M p a})\end{array}$ & $\begin{array}{c}\mathbf{E}_{\mathbf{z}} \\
(\mathbf{M p a})\end{array}$ & $\boldsymbol{\mu}_{\mathbf{x}}$ & $\boldsymbol{\mu}_{\mathbf{y}}$ & $\boldsymbol{\mu}_{\mathbf{z}}$ & $\begin{array}{c}\mathbf{G}_{\mathbf{x y}} \\
(\mathbf{M p a})\end{array}$ & $\begin{array}{c}\mathbf{G}_{\mathbf{y z}} \\
(\mathbf{M p a})\end{array}$ & $\begin{array}{c}\mathbf{G}_{\mathbf{z x}} \\
(\mathbf{M p a})\end{array}$ \\
\hline $\begin{array}{l}\text { Symmetric cross ply laminate } \\
(0 / 90 / 90 / 0)\end{array}$ & 20855 & 20855 & 10410 & 0.17 & 0.282 & 0.282 & 3217.7 & 1100.4 & 2904.6 \\
\hline $\begin{array}{l}\text { Anti-Symmetric cross ply laminate } \\
{[0 / 90 / 0 / 90]}\end{array}$ & 20855 & 20855 & 10410 & 0.17 & 0.282 & 0.282 & 3217.7 & 1100.4 & 2904.6 \\
\hline $\begin{array}{l}\text { Symmetric cross ply laminate } \\
{[-45 / 45 / 45 /-45]}\end{array}$ & 5613.8 & 5613.8 & 2801 & 0.2 & 0.3 & 0.3 & 19835 & 10412 & 15824 \\
\hline $\begin{array}{l}\text { Anti-Symmetric cross ply laminate } \\
{[-45 / 45 /-45 / 45]}\end{array}$ & 5613.8 & 5613.8 & 2801 & 0.2 & 0.3 & 0.3 & 19835 & 10412 & 15824 \\
\hline
\end{tabular}

\section{ANALYSIS USING ANSYS COMPOSITE PREP POST}

Analysis of symmetric and anti-symmetric laminates was carried out using ANSYS ACP (Workbench).

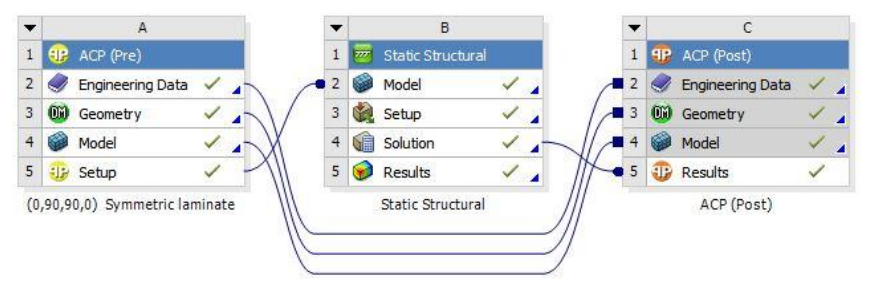

Figure 4: Data Transfer in ANSYS.

The layered composites used in engineering have complex definitions such as numerous material type, layers, orientation and thickness. The challenge in the use of composites lies how good the prediction can be made on its performance in real-world working conditions. Thus, simulation is an ideal means by which the deformations and stresses can be obtained. ANSYS Composite Prep Post software contains necessary functionalities for defining the layered composite structure and for its analysis using the finite element method.

The analysis of the composite ply laminate was carried out in ANSYS using ANSYS (ACP) module. The properties obtained from experimentation such as longitudinal Tension strength, longitudinal compressive strength, transverse Tension strength, transverse compressive strength is given as input ANSYS. The material constants such as Young's modulus; shear modulus and Poisson's ratio are also given as input. The material properties listed in Table.1 are used in the analysis. After meshing (Fig.5), then the model data is transfer to set up where the material data such as material type and thickness is specified. Rosettes (Fig.6) are defined to fix the material axes. The X-axis indicates the longitudinal direction and Y, Z axes represent a transverse direction. Care must be taken while defining it because of the material property changes as the rosette direction changes. Then according to the design of the model, the rosettes need to be specified so that the direction of fibre can be defined accordingly. Then the orientation set is to be defined to give the direction of a layup as shown in Fig.7.In the modelling group, we create plies. The number of plies depends on the thickness of the fabric and the thickness of the 
component needed. The fibre orientation can also be provided while creating the ply. Modelling plies are defined according to the number of plies required or thickness of the composite required. The material properties of the Graphen nano powdered composites are assumed to be incresed by $3 \%$ [16].

Different fibre orientation was considered while carrying out the analysis for different fibre orientation set. The modelled plies are then extruded using the solid models. Thus by using the solid model option, the plies can be represented over the surface, and the thickness of $1.1 \mathrm{~mm}$ is considered.

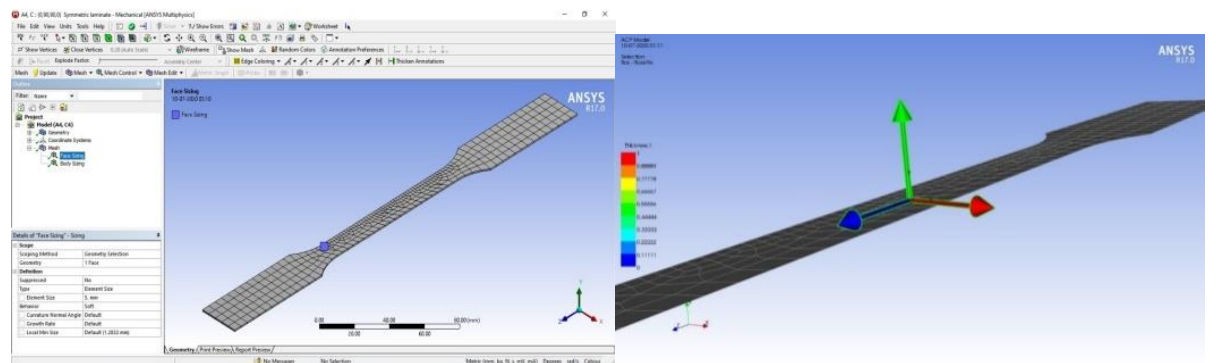

Figure 5: Meshed Model

Figure 6: Rosettes.

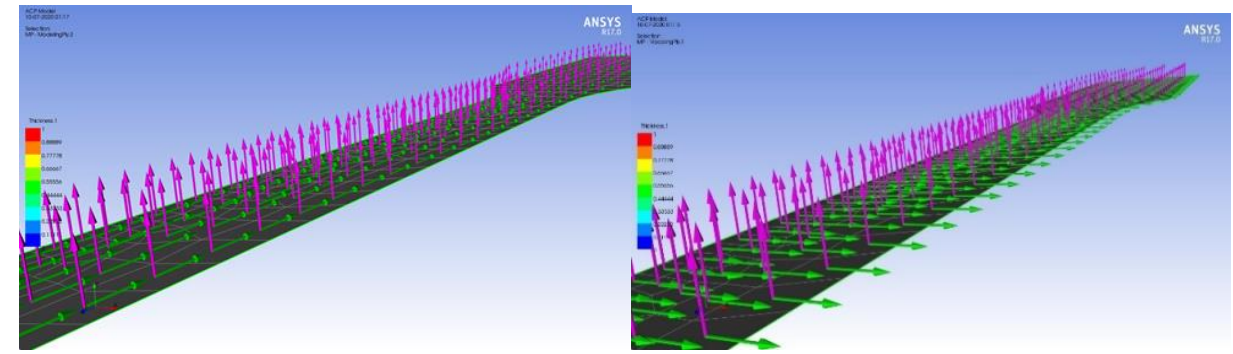

Figure 7.1: Ply 1(Angle $\left.0^{0}\right)$.

Figure 7.2: Ply $2\left(\right.$ Angle $\left.90^{\circ}\right)$.

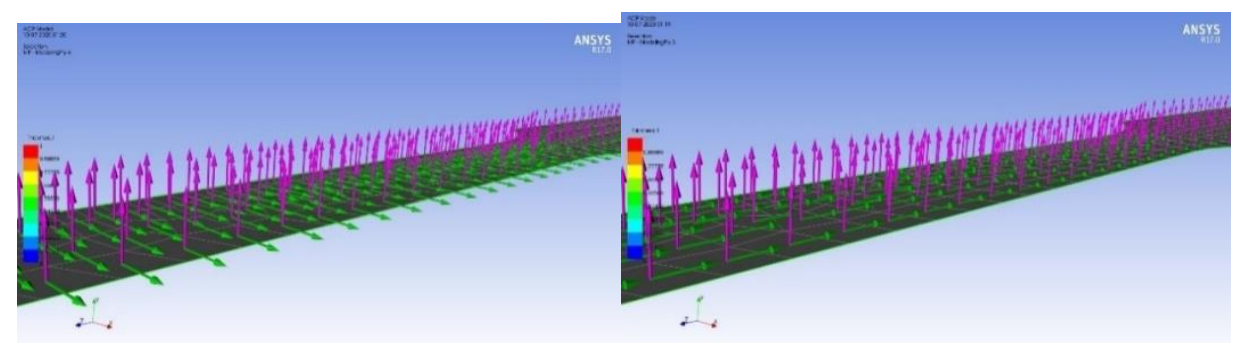

Figure 7.3: Ply 3 (Angle 90 ${ }^{\circ}$ ) Figure 7.4: Ply 4 (Angle $0^{0}$ )

Figure 7: Lay-up of Plies for Symmetric Cross-Ply Laminate [0/90/90/0].

The Loading conditions are given as :Boundary conditions for Tension loading on cross-ply laminate

- The left edge is fixed as all Degree of Freedom.2.Force on right edge $=1000 \mathrm{~N} / \mathrm{mm}$.

- Boundary conditions for Bending loading on cross-ply laminate

- Both left and right edges are fixed as all Degree of Freedom.2.Force on top of the specimen at centre $=200 \mathrm{~N} / \mathrm{mm}$. 
Tension and Bending Analysis for the symmetric cross-ply laminates and anti-symmetric cross-ply laminates [0/90/90/0],[0/90/0/90],[-45/45/45/-45] and [-45/45/-45/45] with and without Graphene nanopowder as the filler material is carried out by considering the size of the laminate according to ASTM standard D3039 using ANSYS ACP. The theoretical analysis also carried by using MATLAB. The results from Tension and bending loads for the laminates with and without Graphene nano powder using ANSYS fort the considered laminates are listed in tables.2.1, 2.2,3.1 and 3.1 respectively.

Table 2: Tension Results of Symmetric and Anti-Symmetric Composite Laminates without Graphene Nanofiller

\begin{tabular}{|c|c|c|c|c|}
\hline S. No & Type of Laminates & Deflection (mm) & Stress (MPa) & Strain \\
\hline 1 & $(0 / 90 / 90 / 0)$ & 2.4074 & 307.53 & 0.017314 \\
\hline 2 & {$[0 / 90 / 0 / 90]$} & 2.4074 & 307.53 & 0.017314 \\
\hline 3 & {$[-45 / 45 / 45 /-45]$} & 4.1932 & 308.64 & 0.033297 \\
\hline 4 & {$[-45 / 45 /-45 / 45]$} & 4.1932 & 308.65 & 0.0333 \\
\hline
\end{tabular}

Table 2.1: Tension Results of Symmetric and Anti-Symmetric Composite Laminates with Graphene Nanofiller

\begin{tabular}{|c|c|c|c|c|}
\hline S. No & Type of Laminates & Deflection $(\mathbf{m m})$ & Stress (MPa) & Strain \\
\hline 1 & $(0 / 90 / 90 / 0)$ & 2.3371 & 307.5 & 0.016797 \\
\hline 2 & {$[0 / 90 / 0 / 90]$} & 2.3371 & 307.51 & 0.016799 \\
\hline 3 & {$[-45 / 45 / 45 /-45]$} & 3.8225 & 312.82 & 0.030296 \\
\hline 4 & {$[-45 / 45 /-45 / 45]$} & 3.8225 & 312.83 & 0.03030 \\
\hline
\end{tabular}

Table 3.12: Bending Results of Symmetric and Anti-Symmetric Composite Laminates without Graphene Nanofiller

\begin{tabular}{|c|c|c|c|c|}
\hline S. No & Type of Laminates & Deflection (mm) & Stress (MPa) & Strain \\
\hline 1 & $(0 / 90 / 90 / 0)$ & 1.2324 & 299.6 & 0.04487 \\
\hline 2 & {$[0 / 90 / 0 / 90]$} & 1.2005 & 284.44 & 0.034949 \\
\hline 3 & {$[-45 / 45 / 45 /-45]$} & 1.5384 & 452.82 & 0.018004 \\
\hline 4 & {$[-45 / 45 /-45 / 45]$} & 1.5386 & 457.96 & 0.018107 \\
\hline
\end{tabular}

Table 3.2: Bending Results of Symmetric and Anti-Symmetric Composite Laminates with Graphene Nanofiller

\begin{tabular}{|c|c|c|c|c|}
\hline S. No & Type of Laminates & Deflection $(\mathbf{m m})$ & Stress (MPa) & Strain \\
\hline 1 & $(0 / 90 / 90 / 0)$ & 1.1973 & 298.39 & 0.04342 \\
\hline 2 & {$[0 / 90 / 0 / 90]$} & 1.1664 & 283.37 & 0.033823 \\
\hline 3 & {$[-45 / 45 / 45 /-45]$} & 1.4438 & 459.24 & 0.016809 \\
\hline 4 & {$[-45 / 45 /-45 / 45]$} & 1.444 & 464.26 & 0.016799 \\
\hline
\end{tabular}

The convergence test results for bending is tabulated in table. 4 and shown in figure 8.

Table 4: Convergence Test for Bending Analysis

\begin{tabular}{|c|c|c|c|c|c|}
\hline S. NO & Element Size $(\mathbf{m m})$ & No of Elements & No of Nodes & Total Deformation $(\mathbf{m m})$ & Error $(\boldsymbol{\%})$ \\
\hline 1 & 5 & 192 & 340 & 1.1423 & - \\
\hline 2 & 4 & 320 & 525 & 1.1612 & 1.726 \\
\hline 3 & 3 & 540 & 840 & 1.1780 & 1.426 \\
\hline 4 & 2 & 1280 & 1845 & 1.1901 & 1.016 \\
\hline 5 & 1 & 5120 & 6885 & 1.1973 & 0.613 \\
\hline
\end{tabular}




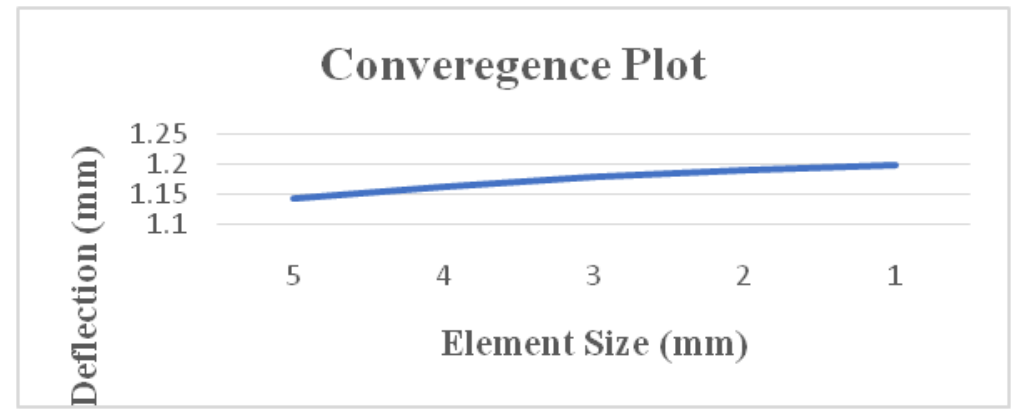

Figure 8: Convergence Plot for Bending.

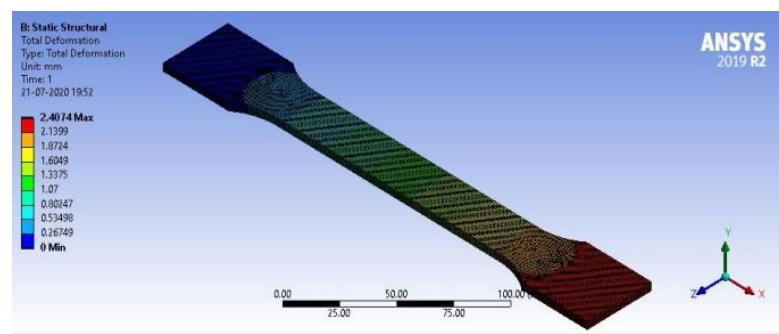

A .With out Graphene Nanopowder

Figure 9.1: Deflection of Anti-Symmetric Laminate [0/90/0/90] under Tension.

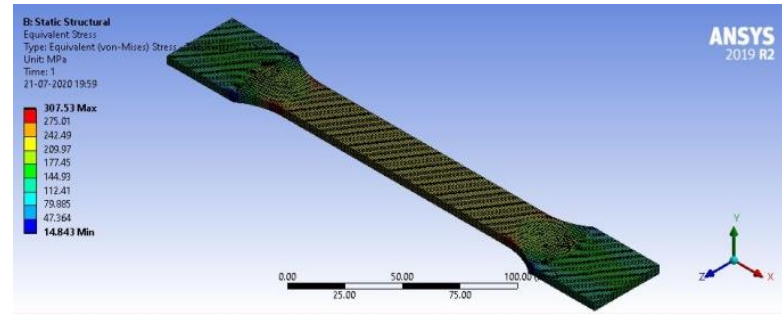

A.withoutgraphene Nanopowder

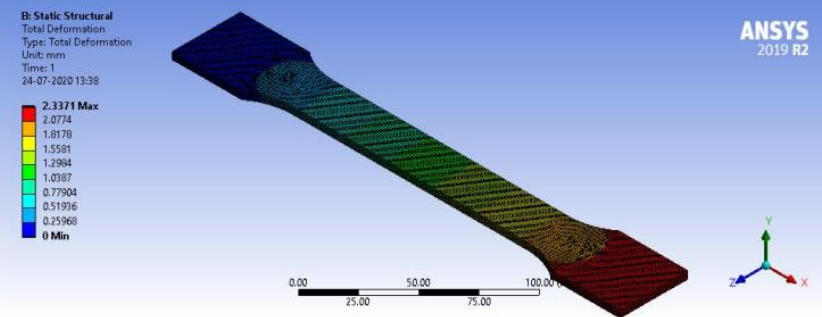

B. With Graphene Nanopowder

b. With Graphene Nanopowder

Figure 9.2:Stress of Anti-Symmetric Laminate[0/90/0/90 under Tension.
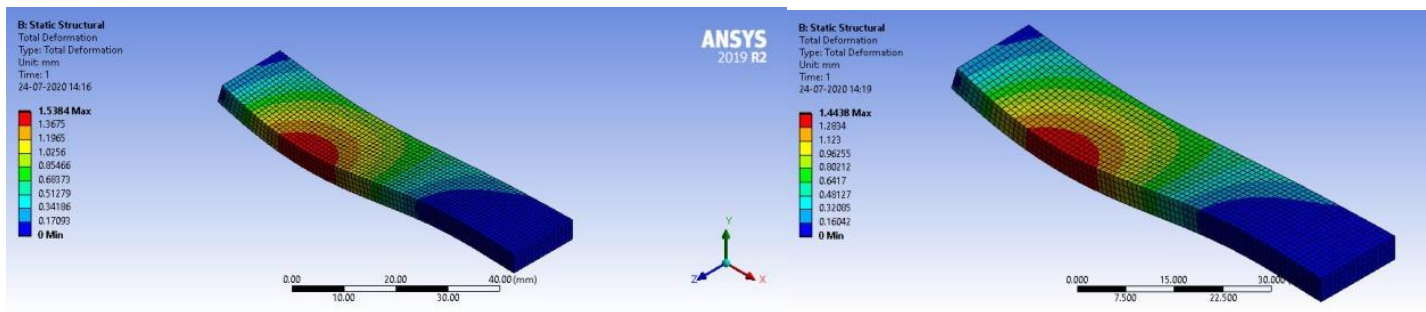

A.without Graphene nanopowderb. with Graphene nanopowder

Figure 10.1: Deflection of Symmetric Laminate[45/45/45/-45] Bending Specimen.

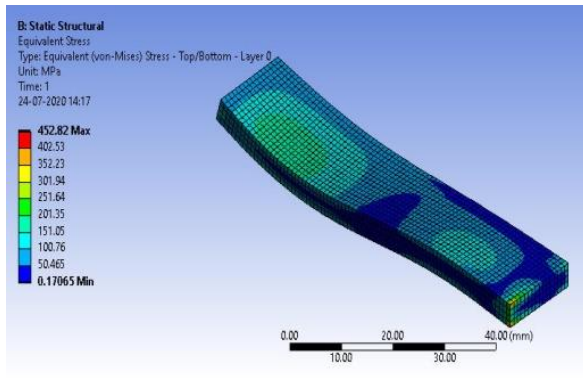

A. without Graphene Nanopowder

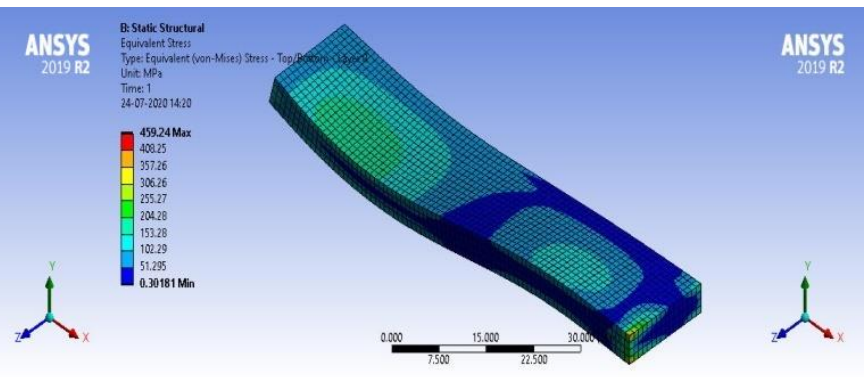

b. with Graphene Nanopowder

Figure 10.2: Stress of Symmetric Laminate[45/45/45/-45] Under Bending. 


\section{CONCLUSIONS}

- It is observed that the addition of graphene nanopowder improves the mechanical bearing capacity of the laminates.

- For the applied maximum tension load of $1000 \mathrm{~N} / \mathrm{mm}$, the symmetric cross-ply laminate with graphene nano powder [0/90/90/0] is observed to be better with maximum deflection $2.3371 \mathrm{~mm}$ and stress developed 307.50 MPa when compared with the other laminates[0/90/0/90], [-45/45/45/-45] and [-45/45/-45/45].

- For the applied maximum bending load of $200 \mathrm{~N} / \mathrm{mm}$, the anti-symmetric cross-ply laminate [0/90/0/90] is observed to be better with maximum deflection $1.1664 \mathrm{~mm}$ and stress developed $283.37 \mathrm{MPa}$ when compared with the other laminates[0/90/90/0],

- $[-45 / 45 / 45 /-45]$ and $[-45 / 45 /-45 / 45]$.

- Under tension in symmetric cross-ply laminate [0/90/90/0] the deflection is reduced from 2.4074 to 2.3371 i.e., $\mathbf{3 \%}$ when graphene nano powder is added for glass-epoxy composites.

- Under bending in anti-symmetric cross-ply laminate [0/90/0/90], the deflection is reduced from 1.2005 to 1.1664 i.e., $\mathbf{2 . 9 \%}$ when graphene nanopowder is added for glass-epoxy composites.

- By theoretical calculations obtained by using MATLAB show the results in a similar trend as obtained using ANSYS ACP.

\section{ACKNOWLEDGEMENTS}

Authors would like to thank theManagement and Principal of Vasavi College of Engineering for their support in carring out this research work.

\section{REFERENCES}

1. TP Sathish kumar,SSatheeshkumar and J Naveen, "Glass fiber-reinforced polymer composites - a review,Journal of Reinforced Plastics and Composites", Submission 2014 33: 1258, April 2014, DOI: 10.1177/0731684414530790.

2. Guru Raja M. $N \&$ A. N. Hari Rao." Effect of an Angle-Ply Orientation on Tensile Properties of Kevlar/glass Hybrid Composites", ISSN : 2319-3182, Volume-2, Issue-3, 2013.

3. Susilendra Mutalikdesai, "Mechanical Characterization of Epoxy/ Basalt Fiber/ Flax Fiber Hybrid Composites. American Journal of Materials Science",submission: 2017, 7(4): 91-94,DOI: 10.5923/j.materials.20170704.04.

4. Christopher P. R. Hoppel and Steven J. De Teresa, "Effect of Angle-Ply Orientation on Compression Strength of Composite Laminates",submitted: April 1999, UCRL-JC-131920.

5. RymTaktak, NoamenGuermazi and TasnimKossentiniKallel, "Effect of E-Glass fibre and ply orientation on the mechanical behaviour of FRP composites used for pressure pipe”, DOI 10.1007/s00170-017-0276-3.

6. J Anjaneyulu, Md. Moizuddin, P Chandra kumar "Evaluation of mechanical behaviour of Glass fibre-epoxy composite laminates". DOI.org/10.1016/j.matpr.2020.03.423.

7. Nagabhushan V Pujar, a, NV Nanjundaradhya, Ramesh S Sharma "Effect of Graphene Oxide Nano Filler on Dynamic Behaviour of GFRP Composites".

8. L. Kashinath, R. Senthil Kumar, Y. Hayakawa, G. Ravi "Synthesis \& Structural Study on Graphene Nano Particles". 
9. G. Rathinasabapathi, A. Krishnamoorthy "Reinforcement Effect of Graphene Enhanced Glass Fibre Reinforced Polymers: A Prominence On Graphene Content".

10. M. Elkington, D.Bloom, C.Ward, A.Chatzimichali and K.Potter "Hand layup: understanding the manual process", submission 1:3, 138-151,2015,DOI:10.1080/20550340.2015.1114801. 
